\title{
FOXM1 is overexpressed in B-acute lymphoblastic leukemia (B-ALL) and its inhibition sensitizes B-ALL cells to chemotherapeutic drugs
}

\author{
FRANCESCA CONSOLARO $^{1,2}$, GIUSEPPE BASSO ${ }^{1}$, SADAF GHAEM-MAGAMI $^{2}$, \\ ERIC W.-F. LAM ${ }^{2}$ and GIAMPIETRO VIOLA ${ }^{1}$
}

\author{
${ }^{1}$ Department of Woman's and Child's Health, Oncohematology Laboratory, University of Padova, Padova, Italy; \\ ${ }^{2}$ Department of Surgery and Cancer, Imperial College London, \\ Imperial Centre for Translational and Experimental Medicine (ICTEM), London, UK
}

Received May 11, 2015; Accepted June 10, 2015

DOI: 10.3892/ijo.2015.3139

\begin{abstract}
The Forkhead box protein M1 (FOXM1) is a transcription factor that plays a central role in the regulation of cell cycle, proliferation, DNA repair, and apoptosis. FOXM1 is overexpressed in many human tumors and its upregulation has been linked to high proliferation rates and poor prognosis. We therefore studied the role of FOXM1 in B-lymphoblastic leukemia (B-ALL) in order to understand whether FOXM1 could be a key target for leukemia therapy. RT-PCR and western blot analysis were carried out in a small cohort of pediatric B-ALL patients to evaluate FOXM1 levels. To assess its biological relevance, its expression was down-modulated by transient RNA interference in B-ALL cell lines (REH and NALM-6). Our results show that FOXM1 expression is higher in both B-ALL patients and cell lines when compared to PBMC or normal B-cells $\left(\mathrm{CD} 19^{+}\right)$from healthy donors. Furthermore, blocking FOXM1 activity in two B-ALL cell lines, by either knockdown or treatment with the FOXM1 inhibitor thiostrepton, causes significant decrease in their cell proliferation. This decrease in cell proliferation was coupled with both an induction of the G2/M cell cycle arrest and with a reduction in the S phase population. Finally, we noted how thiostrepton synergises with chemotherapeutic agents commonly used in B-ALL therapy, thus increasing their efficiency. Therefore our results suggest that FOXM1 is highly expressed in both
\end{abstract}

Correspondence to: Professor Eric W.-F. Lam, Department of Surgery and Cancer, Imperial College London, Imperial Centre for Translational and Experimental Medicine (ICTEM), London, UK E-mail: eric.lam@imperial.ac.uk

Dr Giampietro Viola, Dipartimento di Salute della Donna e del Bambino, Laboratorio di Oncoematologia, Università di Padova, Padova, Italy

E-mail: giampietro.viola.1@unipd.it

Key words: FOXM1, B-acute lymphoblastic leukemia, chemotherapy, drug resistance, thiostrepton patients and B-ALL cell lines, and that targeting FOXM1 could be an attractive strategy for leukemia therapy and for overcoming drug resistance.

\section{Introduction}

FOXM1 is a member of the Forkhead family of transcription factors, previously known as Trident (in mouse), HFH-11 (in human), WIN or INS-1 (in rat), MPP-2 (partial human cDNA) and FKHL-16 (1). FOXM1 is a potent oncogene whose expression is frequently upregulated during cancer initiation. FOXM1 expression increases at the entry of the S-phase of the cell cycle, remains stable during G2/M phase, before being degraded at the mitotic exit $(2,3)$. FOXM1 also controls mitosis through the transcriptional regulation of mitotic regulatory genes, including PLK, Cyclin B1, Aurora A and B kinases (4), and in addition, it plays a major role in maintaining chromosome stability (2). FOXM1 has an important role in cell cycle progression and cell proliferation. As such, its expression levels correlate with the proliferative state of a cell. Not surprisingly, FOXM1 is highly expressed in all embryonic tissues, particularly in proliferating cells of epithelial and mesenchymal origin (5). Its overexpression has also been detected in numerous human cancer cell lines and has been associated with the development and progression of many malignancies $(6,7)$, with high cell proliferation rates, drug resistance (8-10) and poor prognosis in many cancer types (11-15).

B-lymphoblastic leukemia (B-ALL) is a malignant disorder which derives from clonal proliferation of lymphoid precursors with arrested maturation. In recent years the role and involvement of FOXM1 in B-ALL and other hematological malignancies has become increasingly important. A previous study by Nakamura et al has examined the role of FOXM1 in cell proliferation in myeloid leukemia, showing its capability to promote cell cycle progression (16). Other studies have also demonstrated that FOXM1 downregulation causes the inhibition of cell proliferation in B-lymphoma (17). A different report by Uddin et al has instead described the involvement of FOXM1 in B-cell lymphoma migration and invasion (18), and recently it has been pointed out that FOXM1 pathway could be 
a potential therapeutic target in B cell malignancy $(19,20)$. The role of FOXM1 as an oncogene and its upregulation in relapsed B-ALL patients (21), prompted us to investigate whether FOXM1 has a potential role in B-ALL cell proliferation, with particular focus on whether it can become a target that would increase the efficiency of chemotherapeutic treatment, and allow us to overcome drug resistance in this hematological malignancy.

\section{Materials and methods}

Primary leukemia cell cultures. The mRNA and protein samples of PBMC from healthy donors were obtained from cells separated by Ficoll-Paque centrifugation, while healthy B-cells (mainly CD19+) were obtained by cell sorting of bone marrows from healthy volunteers. Diagnostic RNA samples of bone marrow (BM) aspirates of B-leukaemic patients with a blast count of $80-95 \%$ were kindly allowed from the Cell Bank of the Dipartimento di Salute della Donna e del Bambino, University of Padova, Italy. B-ALL patient samples were obtained after informed consent following the tenets of the Declaration of Helsinki. The study was approved by the Italian Association of Pediatric Onco-Hematology (AIEOP). Written consent was obtained from participants. All analyzed B-ALL samples were obtained at the time of diagnosis before treatment, after Ficoll-Hypaque (Pharmacia, Uppsala, Sweden) separation of mononuclear cells as described previously (22). The percentage of $\mathrm{CD}_{1} 9^{+}$cells ranged from 80 to $95 \%$. Human B-leukemia cell lines, REH, SEM, MHH-CALL2, RS4;11 and NALM-6, were grown in RPMI-1640 medium (Gibco, Milan, Italy) all supplemented with $115 \mathrm{U} / \mathrm{ml}$ penicillin $\mathrm{G}$ (Gibco), $115 \mu \mathrm{g} / \mathrm{ml}$ streptomycin (Invitrogen), 10\% fetal bovine serum (Invitrogen), and maintained at $37^{\circ} \mathrm{C}$ in a humidified atmosphere with $5 \% \mathrm{CO}_{2}$.

Quantitative real-time PCR. Total RNA was isolated from frozen cell pellets using the RNeasy Mini kit (Qiagen, UK) according to the manufacturer's instructions and RNA purity and concentration were determined by measuring the spectrophotometric absorption at $260 \mathrm{~nm}$ and $280 \mathrm{~nm}$ on NanoDrop ND-1000. Total RNA $(1 \mu \mathrm{g})$ was reverse transcribed into first strand cDNA using Superscript III first stand cDNA synthesis (Life Technologies, UK) Briefly, $1 \mu \mathrm{l}$ of $50 \mu \mathrm{M}$ oligo(dT)20 and $1 \mu \mathrm{l}$ of $10 \mathrm{mM}$ dNTPs mix were added to the RNA before the volume was adjusted to $11 \mu \mathrm{l}$ using RNase-free water. Samples were denaturated at $65^{\circ} \mathrm{C}$ for 5 min and then quickly chilled on ice for $1 \mathrm{~min}$. Subsequently, $1 \mu \mathrm{l}$ of the reverse transcriptase Superscript III (200 U/ $\mu \mathrm{l})$ was added, along with $1 \mu \mathrm{l}$ $0.1 \mathrm{M}$ DTT, $1 \mu \mathrm{l}$ RNaseOUT Recombinase Inhibitor and $1 \mathrm{X}$ first stand buffer. The solution was incubated at $25^{\circ} \mathrm{C}$ for $5 \mathrm{~min}$ then heated at $50^{\circ} \mathrm{C}$ for $50 \mathrm{~min}$. The reaction was inactivated by heating at $70^{\circ} \mathrm{C}$ for $15 \mathrm{~min}$. For real-time quantitative PCR, $1 \mu \mathrm{l}$ of cDNA was used as template in a $24-\mu 1$ reaction carried out with Power SYBR Green kit (Applied Biosystems, UK) with ABI 7800 system (Applied Biosystems). The mRNA levels of target genes were calculated relative to the expression of L19 mRNA levels using the $\Delta \mathrm{Ct}$ method. Primers used: FOXM1-fwd, 5'-TGCAGCTAGGGATGTGAATCTTC-3'; FOXM1-rv, 5'-GGAGCCCAGTCCATCAGAACT-3'; $C C N B 1-f w d$, 5'-CAGTTATGCAGCACCTGGCTAAG-3';
CCNB1-rv, 5'-TGTGGTAGAGTGCTGATCTTAGCAT-3'; $A U R K B-f w d, 5$ '-AGTGGGACACCCGACATC-3'; AURKB-rv, 5'-GCCCA ATCTCAA AGTCATCAATT-3'; $L 19-f w d$, 5'-GCGGAAGGGTACAGCCAAT-3'; L19-rv, 5'-GCAGCC GGCGCAAA-3'.

Western blot analysis. REH, SEM, MHH-CALL2, RS4;11 and NALM-6, after experimental conditions, were collected, centrifuged, and washed two times with ice cold phosphatebuffered saline (PBS). For western blot analysis cells were lysed as described previously (23). Proteins were resolved by sodium dodecyl sulphate-polyacrylamide gel electrophoresis (SDS-PAGE) (using 7 or $10 \%$ acrylamide gels), transferred to PVDF Hybond-P membrane (GE Healthcare) and immunoblotted with primary antibodies against, FOXM1 (Santa Cruz, C-20), $\beta$-tubulin (Santa Cruz), Aurora B (Cell Signaling), Cyclin B1 (Santa Cruz). The membranes were washed four times with Tris-buffered saline and Tween-20 (TBS-T) for 15 min prior to incubation with the respective peroxidise (HRP)-conjugated secondary antibody (Dako, Ely, UK), at 1:2,000 dilution for $30 \mathrm{~min}$ at room temperature and again washed four times with TBST-T for $20 \mathrm{~min}$. Protein were visualised using enhanced chemiluminescence (ECL) detection system (Perkin-Elmer, Seer Green, UK) with Amsterdam Hyperfilm ECL (GE Helthcare, Little Chalfont, UK) and signal was detected using the SRX-101A X-ray developer (Konica Minolta, Tokyo, Japan).

RNA interference with small interfering RNAs (siRNAs). For FOXM1 silencing, REH or NALM-6 cells were transiently transfected with siRNA SMARTpool reagents purchased from Thermo Scientific Dharmacon (Lafayette, CO, USA) using the transfection reagent Oligofectamine (Life Technologies, UK) according to the manufacturer's instructions. SMARTpool siRNAs used were: siRNA FOXM1 (1-009762-00) and the non-specific (NS) control siRNA, ON-TARGETplus Non-Targeting pool (D-001810-10) confirmed to have minimal targeting of known genes. All siRNA pools were resuspended to $20 \mu \mathrm{M}$ in $1 \mathrm{X}$ siRNA buffer.

Annexin V assay. Surface exposure of phosphatidylserine on apoptotic cells was measured by flow cytometry with a Coulter Cytomics FC500 (Beckman Coulter) by adding Annexin V conjugated to fluorescein isothiocyanate (FITC) to cells according to the manufacturer's instructions (Annexin V Fluos, Roche Diagnostic). Simultaneously, the cells were stained with PI. Excitation was set at $488 \mathrm{~nm}$, and the emission filters were at 525 and $585 \mathrm{~nm}$, respectively, for FITC and PI.

Flow cytometric analysis of cell cycle distribution. For flow cytometric analysis of DNA content, $5 \times 10^{5}$ of REH, and NALM- 6 cells were either treated with 0.5 and $1 \mu \mathrm{M}$ of thiostrepton or knocked-down for FOXM1 and after 24, 48 and $72 \mathrm{~h}$ of treatment or knockdown, cell cycle analysis was performed as previously described (24).

Drug combination studies. Cell proliferation was assessed by MTT (3-4,5-dimethylthiazol-2-yl-2,5-diphenyl tetrazolium bromide) assay after treatment. Equal concentrations of cells were plated in triplicate in a 96-well plate and incubated with 
A
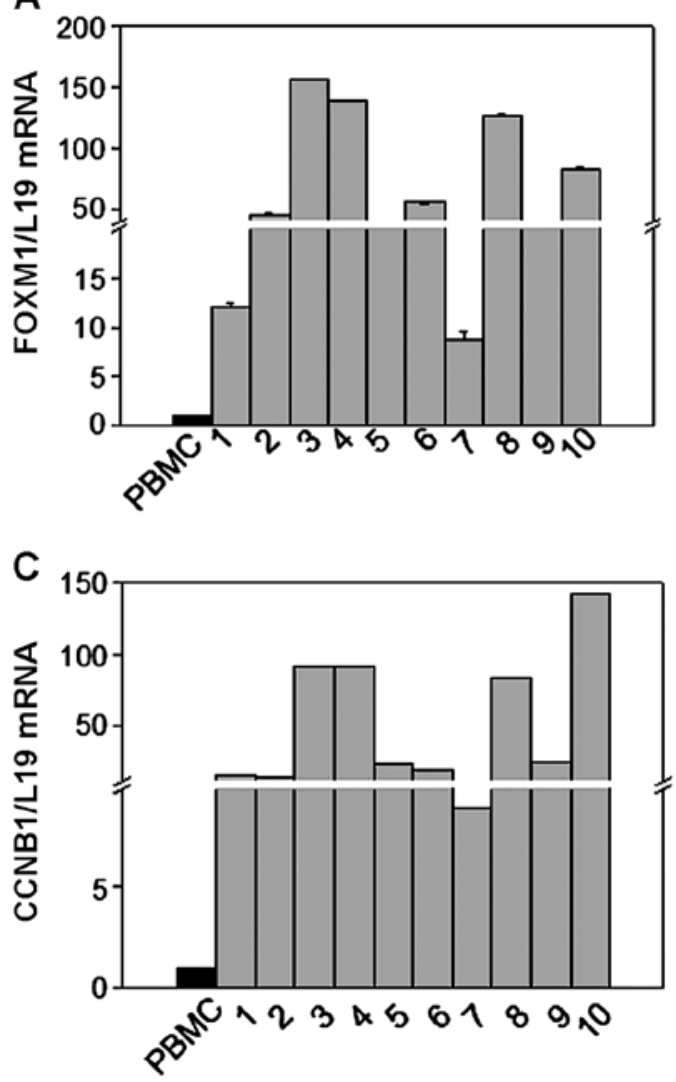

B

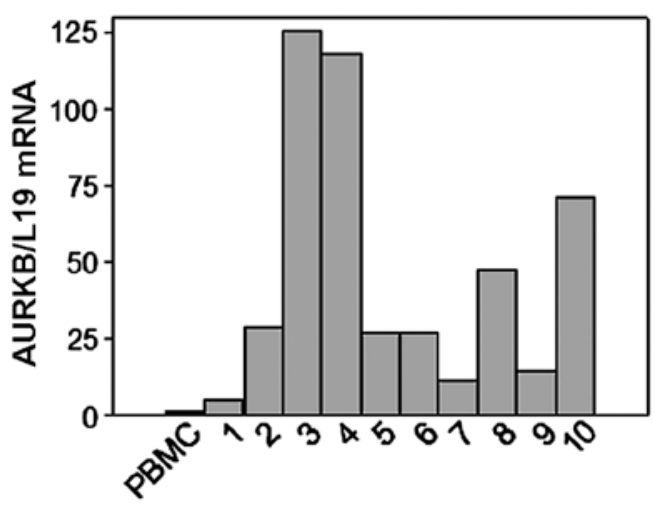

D

Figure 1. FOXM1 is higher expressed in B-ALL patients compared to healthy donors. (A-C) Basal FOXM1, AURKB and CCNB1 mRNA levels were analyzed in ten samples of B-ALL patients and compared to peripheral blood mononuclear cells (PBMC) of healthy donors by RT-qPCR. The results were normalised with L19 mRNA levels using the $\Delta \Delta \mathrm{Ct}$ method. The median of threshold cycles $(\mathrm{Ct})$ values was normalized to the median of Ct values of the L19 mRNA levels. Results are the average \pm SD of three independent experiments in triplicate. (D) Cell lysates were obtained from ten B-ALL patients and analyzed for the expression of FOXM1 and its downstream target genes Cyclin B1 and Aurora B in comparison to PBMC.

$10 \mu \mathrm{l}$ of MTT (Sigma-Aldrich, St. Louis, MO, USA) for $4 \mathrm{~h}$. Absorbance was measured at $562 \mathrm{~nm}$ using Victor3 ${ }^{\mathrm{TM}} 1420$ Multilabel Counter (Perkin-Elmer, Waltham, MA, USA). Cells were treated for $48 \mathrm{~h}$ using scalar dilutions of thiostrepton (Sigma-Aldrich), combined with cytarabine (Aractyn, Pfizer), daunorubicin (Pfizer), vincristine, dexamethasone (SigmaAldrich). Thiostrepton was also added to drug solutions at fixed combination ratios. The effectiveness of various drug combinations was analyzed by Calcusyn Version 2.1 software (Biosoft). The combination index (CI) was calculated according to the Chou-Talalay method (25). A combination index of 1 indicates an additive effect of the 2 drugs. Combination index values $<1$ indicate synergy, and combination index values $>1$ indicate antagonism.

Statistical analysis. Results are presented as the mean \pm SEM. The differences between different conditions were analyzed using the two-sided Student's t-test. P-values $<0.05$ were considered statistically significant.

\section{Results}

FOXM1 is overexpressed in B lymphoblastic leukaemic patients. To investigate whether FOXM1 regulates B lymphoblastic leukemia (B-ALL) proliferation, we analyzed FOXM1 mRNA levels in ten B-ALL pediatric patients comparing them
Table I. Characteristics of patients samples.

\begin{tabular}{lcccc}
\hline $\begin{array}{l}\text { B-ALL } \\
\text { sample }\end{array}$ & Gender & $\begin{array}{c}\text { Age at } \\
\text { diagnosis }\end{array}$ & $\begin{array}{c}\text { \% of blast } \\
\text { in BM }\end{array}$ & Cytogenetics \\
\hline$\# 1$ & $\mathrm{~F}$ & 6 & 82 & $9 \mathrm{q} 22$ \\
$\# 2$ & $\mathrm{M}$ & 16 & 91 & $9 \mathrm{q} 22$ \\
$\# 3$ & $\mathrm{~F}$ & 5 & 77 & $12 \mathrm{q} 21$ \\
$\# 4$ & $\mathrm{M}$ & 3 & 90 & $12 \mathrm{q} 21$ \\
$\# 5$ & $\mathrm{~F}$ & 3 & 63 & $12 \mathrm{q} 21$ \\
$\# 6$ & $\mathrm{~F}$ & 8 & 97 & Normal \\
$\# 7$ & $\mathrm{M}$ & 1 & 89 & Normal \\
$\# 8$ & $\mathrm{~F}$ & 8 & 90 & Normal \\
$\# 9$ & $\mathrm{M}$ & 4 & 90 & Normal \\
$\# 10$ & $\mathrm{M}$ & 2 & 89 & Normal \\
\hline
\end{tabular}

to peripheral blood mononuclear cells (PBMC) from healthy donors. For these experiments, the mRNA was extracted from cell pellets of patients recruited at the time of diagnosis. The first two selected patients were characterized by chromosomal translocations at chromosome 12 and 21 [t(12;21)]; patients 3, 4 and 5 carried the translocation between the chromosome 9 and 22 [t $(9 ; 22)]$, whereas the other five patients were without translocations (Table I). As shown in Fig. 1A, FOXM1 mRNA 
A

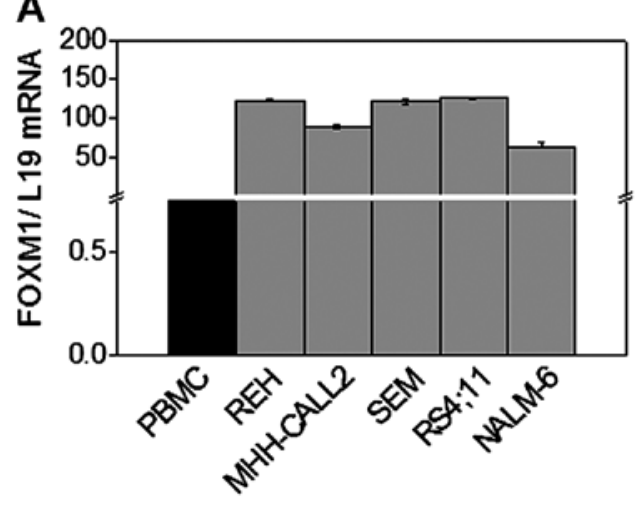

C

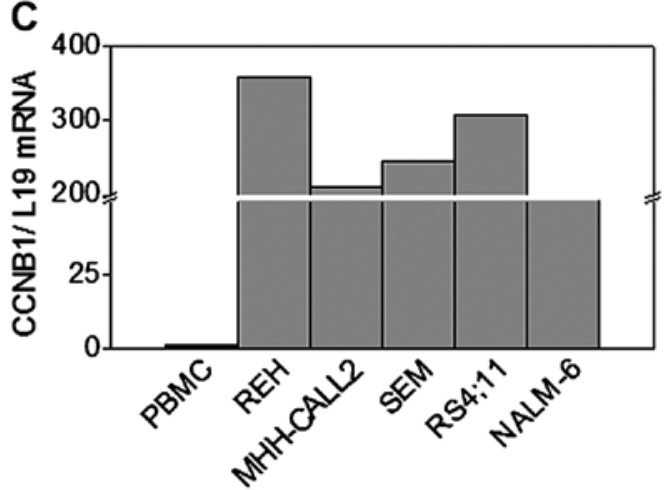

B

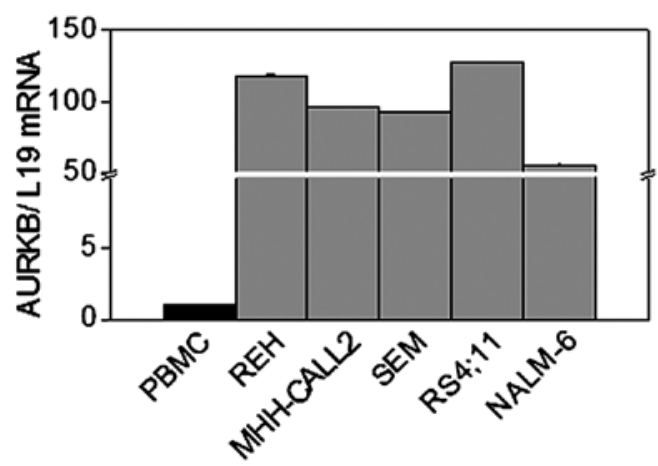

D

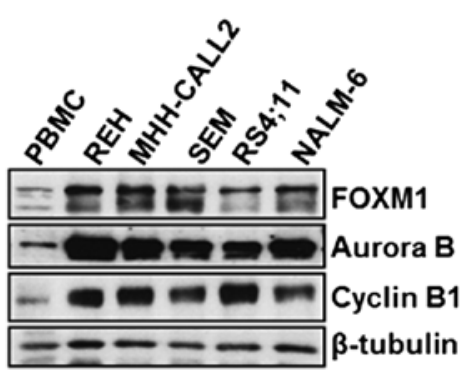

Figure 2. Expression of the FOXM1 is higher in B-ALL cell lines compared to healthy donors. (A-C) Basal FOXM1, AURKB and CCNB1 mRNA levels were analyzed in five B-ALL cell lines (REH, MHH-CALL2, SEM, RS4;11, NALM-6) and compared to peripheral blood mononuclear cells (PBMC) of healthy donors by RT-qPCR. Results are the average \pm SD of three independent experiments in triplicate. (D) REH, MHH-CALL2, SEM, RS4;11, NALM-6 cell lysates were collected at basal conditions for subsequent western blot analysis for the indicated antibodies.

levels were significantly higher in patients when compared to the samples of healthy donors. Interestingly, a significant increment on Cyclin B1 and Aurora B mRNA levels, two genes whose expression is directly regulated by FOXM1 was also observed (Fig. 1B and C). In addition to mRNA levels, protein expression was also examined by western blot analysis. As shown in Fig. 1D, the expression of FOXM1 and of its targets Aurora B and Cyclin B1 was generally higher in patients compared to healthy cells, confirming the upregulated FOXM1 activity. Similar results were obtained when the mRNA or protein levels of B-ALL patients were compared to those of CD19-positive cells isolated from bone marrows of healthy donors (data not shown). Taken together, these data showed that the expression levels and activity of FOXM1 are increased in B-ALL patient samples when compared to healthy lymphocytes and normal B-cells, suggesting that FOXM1 could plays a key function in supporting the cell proliferation of B-ALL.

FOXM1 is overexpressed in B-ALL cell lines. Next, we analyzed FOXM1 expression levels in five different B-ALL cell lines. More specifically, we quantified FOXM1 mRNA levels, at basal conditions, comparing five different B-ALL cell lines (REH, MHH-CALL2, SEM, NALM6, RS4;11) with mRNA samples of PBMC obtained from healthy donors. RT-qPCR analysis showed in Fig. 2A reveals that FOXM1 mRNA levels were significantly higher in B-ALL cell lines when compared to normal lymphocytes. This pattern was again accompanied by increased transcriptional levels of Cyclin B1 and Aurora B (Fig. 2B and C). In agreement with the mRNA expression patterns, western blot analysis revealed that FOXM1 expression was generally higher in leukaemic cells compared to normal lymphocytes. This was again associated with Cyclin B1 and Aurora B upregulation in leukaemic cells (Fig. 2D). Similar results were obtained comparing the FOXM1 mRNA and protein expression of B-ALL cell lines with healthy $\mathrm{CD}_{1}{ }^{+}$cells (data not shown).

FOXM1 silencing decreases cell proliferation in B-ALL cell lines and induces a G2/M cell cycle arrest. To test if FOXM1 has a role in promoting B-ALL proliferation, we knocked down its expression in two B-ALL cell lines REH and NALM-6 using a specific FOXM1 siRNA pool and assessed the cell viability at 24,48 , and $72 \mathrm{~h}$ post-transfection. FOXM1 silencing was confirmed by western blot and RT-qPCR analysis (Fig. 3A-D). Aurora B and Cyclin B1 protein levels were clearly downregulated in FOXM1-depleted NALM-6 and REH cells compared to cells transfected with non-specific (NSC) control siRNA pool (Fig. 3A and B). Furthermore, in both REH and NALM-6 cell lines, RT-qPCR analysis revealed a significant decrease in Aurora B mRNA levels, although Cyclin B1 mRNA levels appeared significantly decreased only in REH and not in NALM-6 cells (Fig. 3C and D).

Cell proliferation analysis assessed by trypan blue exclusion assay, revealed that upon FOXM1 depletion, there is a significant decrease in cell proliferation after $72 \mathrm{~h}$ of trans- 

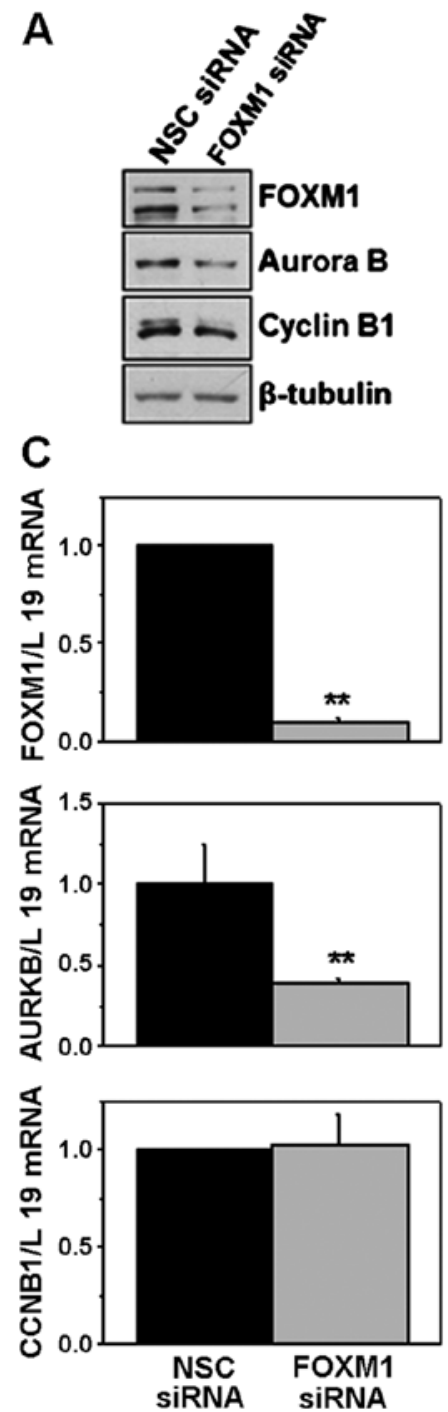
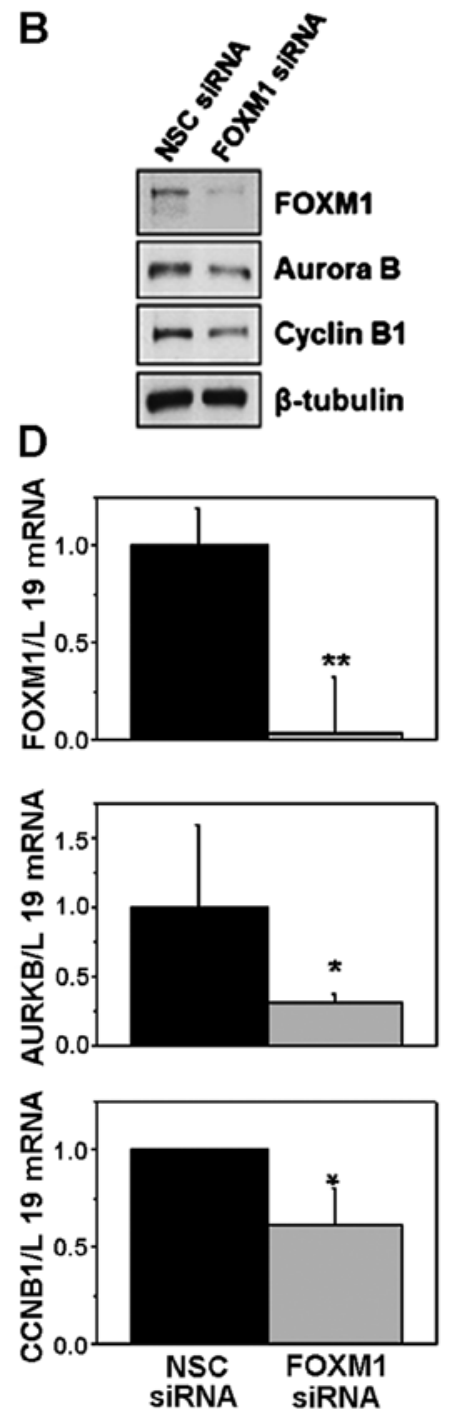

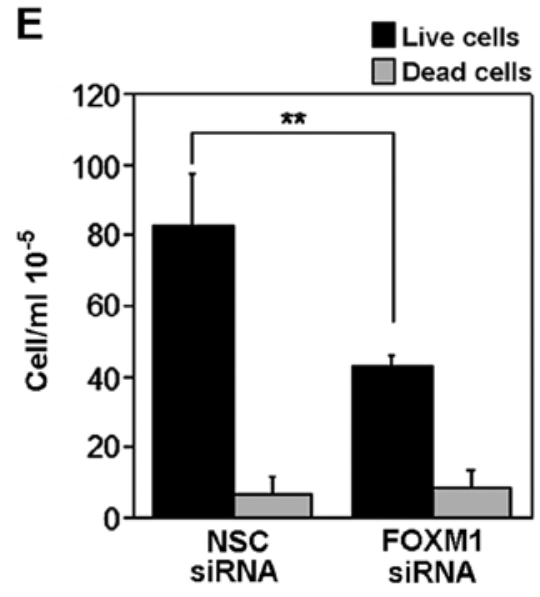

$\mathbf{F}$
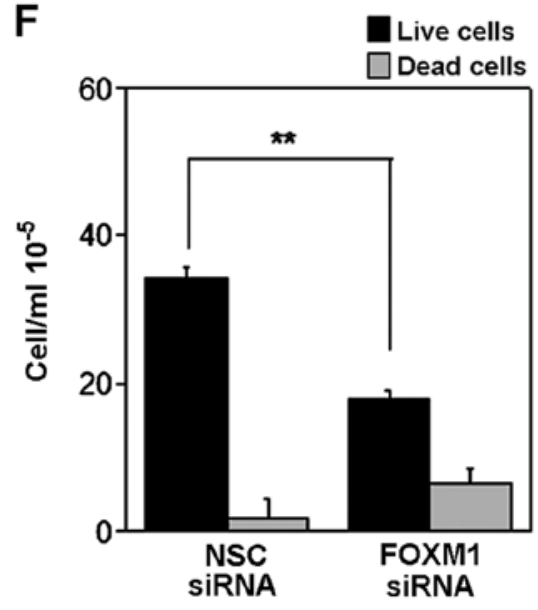

Figure 3. FOXM1 knockdown in REH and NALM6 cells induces a significant decrease in cell proliferation. NALM-6 (A) and REH (B) were transfected with the siRNA FOXM1 and the non-specific (NSC) control siRNA. Western blot analysis and RT-qPCR confirmed the knockdown of endogenous FOXM1 and the reduced expression of Aurora B and Cyclin B1 in NALM-6 cells (A-C) and REH cells (B-D). Cell viability analysis, was performed by trypan blue assay, after $72 \mathrm{~h}$ of transfection in NALM-6 (E) and after $48 \mathrm{~h}$ of transfection in REH (F). Data are presented as mean \pm SD of three independent experiments. Statistical analysis was performed using Student's t-tests against the cells transfected with the non-specific (NS) control siRNA. ${ }^{*} \mathrm{p} \leq 0.05,{ }^{* *} \mathrm{p} \leq 0.01$.

fection in NALM-6 (Fig. 3E) and after $48 \mathrm{~h}$ in REH cells (Fig. 3F), suggesting that FOXM1 plays an important role in B-ALL cell proliferation. Trypan blue-negative population (live cells) was strongly decreased in cells that were silenced for FOXM1, with no significant changes in the levels of dead cells (trypan blue-positive) in NALM-6, and only with a slight increase in the percentage of dead cells in REH. These results pointed out that FOXM1 plays an important role in B-ALL cell proliferation.

To further analyze the role of FOXM1 on cell cycle progression in B-ALL, we analyzed the cell cycle phase distribution in NALM-6 and REH cells following FOXM1 knockdown. As shown in Fig. 4A and B, there was a significant increase on the percentage of cells in $\mathrm{G} 2 / \mathrm{M}$ in both cell lines, and a corresponding decrease of cells in the $S$ phase compared with non-specific (NSC) control cells, only in NALM-6 cells at 72 h. The G2/M cell cycle arrest following FOXM1 silencing by siRNA is confirmed by the consistent downregulation of the expression of the G2/M regulators, Cyclin B1 and Aurora B (Fig. 4C and D). This further supports the role of FOXM1 in cell cycle progression in B-ALL, particularly at the G2/M transition.

FOXM1 silencing reduces the expression of cell cycle regulators. We next evaluated if FOXM1 knockdown could modulate the expression of proteins involved in late phase cell cycle regulation. As depicted in Fig. 4, the FOXM1 silencing in both NALM-6 (Fig. 4C) and in REH cells (Fig. 4D), caused downregulation of cell cycle regulatory proteins such as Cyclin B1, Aurora B, Survivin, and Cdc25b, involved in mitotic progression. The expression of the S-phase promoting $\mathrm{Cdc} 25$ a phosphatase, which plays a major role in $\mathrm{G} 1 / \mathrm{S}$ progression, dephosphorylating $\mathrm{Cdk} 2$ and activating CDK2-cyclin E activity $(26,27)$, was strongly reduced. Interestingly, both $\mathrm{p} 27^{\mathrm{Kip} 1}$ and $\mathrm{p} 21^{\mathrm{Cip} / \text { Waf1 }}$, were also downregulated. These two cyclin-dependent kinase inhibitor (CKI) proteins also play a 
A
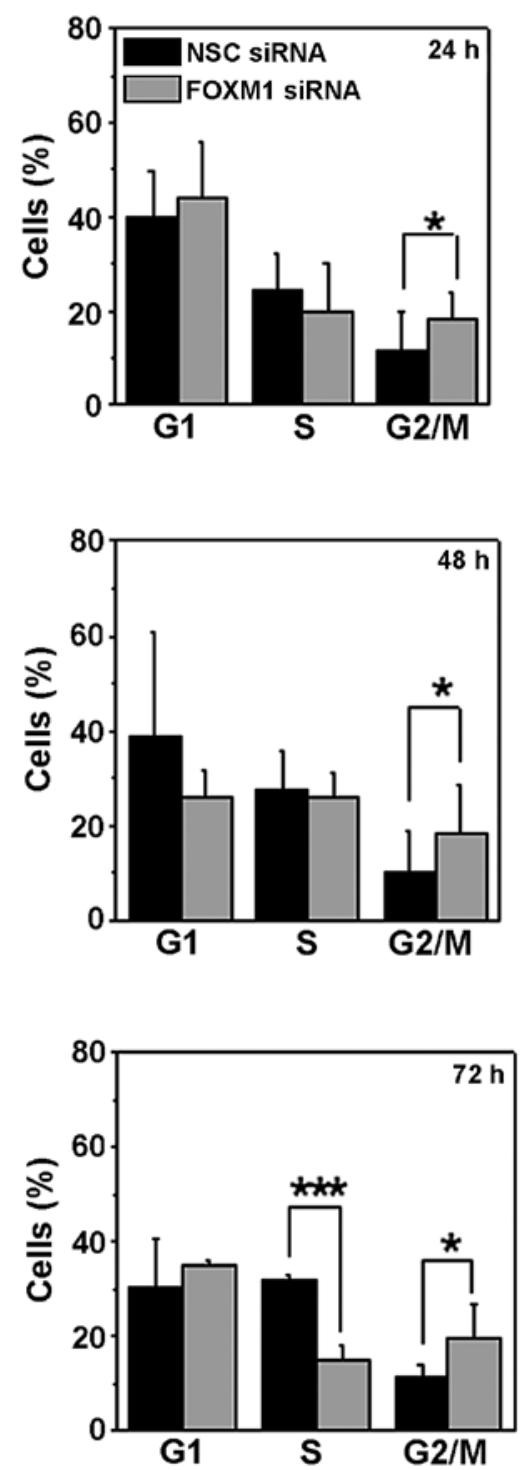

B
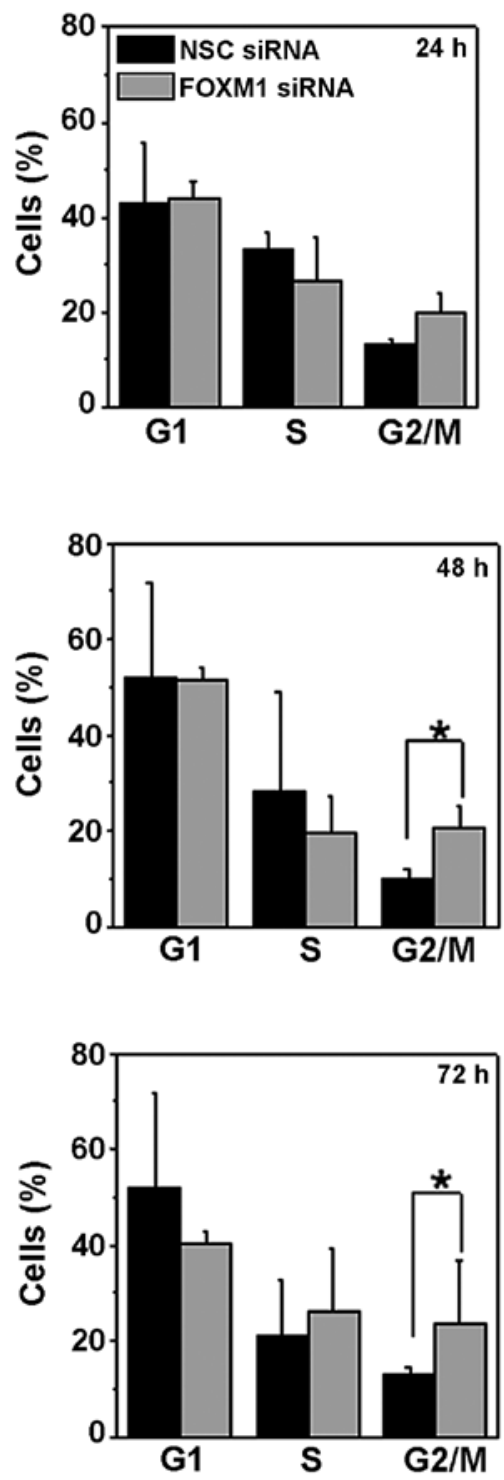

C

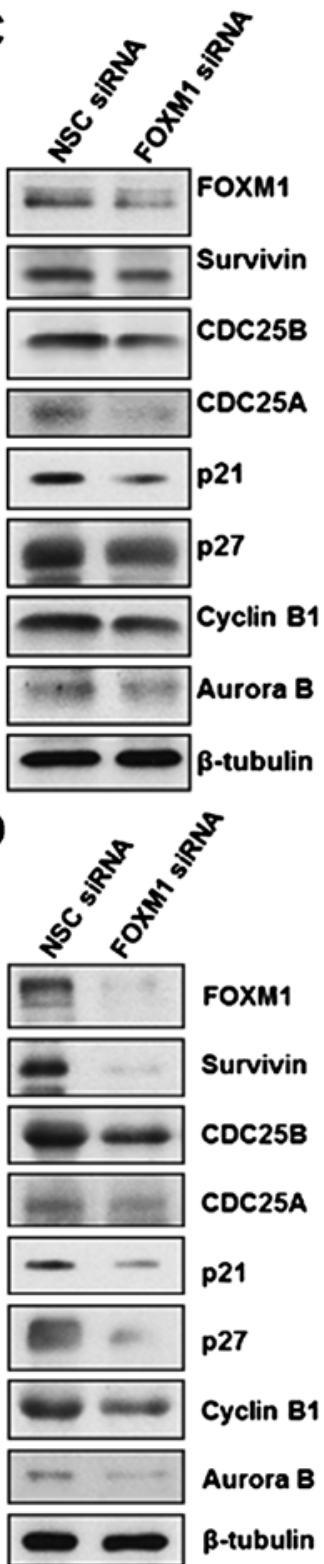

Figure 4. FOXM1 downregulation in REH and NALM6 cells by a specific FOXM1 siRNA pool induces a G2/M cell cycle arrest. In NALM-6 (A) and REH cell (B) lines the endogenous FOXM1 expression was blocked by knockdown performed using Oligofectamine ${ }^{\mathrm{TM}}$ Transfection protocol. After 24,48 and $72 \mathrm{~h}$ of knockdown, cell cycle analysis was performed to investigate the effect of FOXM1 inhibition in cell cycle-phase progression. Results are the average \pm SD of three independent experiments in triplicate. Statistical analysis was performed using Student's t-tests against the cells transfected with the non-specific (NSC) siRNA. ${ }^{*} \mathrm{p} \leq 0.05,{ }^{* *} \mathrm{p} \leq 0.01,{ }^{* * *} \mathrm{p} \leq 0.001$. Effect of FOXM1 knockdown on the expression of proteins involved in cell cycle regulation. In NALM-6 (C) and REH (D) cell lines the endogenous FOXM1 expression was blocked by knockdown and after $48 \mathrm{~h}$, cells were collected, and protein extracts were subjected to western blot analysis for the indicated antibodies.

role in the assembly of cyclin-CDK complexes. Altogether, these results indicate that FOXM1 is strongly involved in modulating the expression of cell cycle regulatory proteins at both the G1/S and at the G2/M cell cycle transitions.

Thiostrepton treatment induces G2/M arrest and decreased cell viability. To further confirm the role of FOXM1 on B-ALL cell proliferation, we treated cells with the thiazole ring containing antibiotic, thiostrepton, a well-established specific FOXM1 inhibitor $(28,29)$. This drug causes growth inhibition in a small panel of B-ALL cell lines with $\mathrm{GI}_{50}$ in the micromolar and sub-micromolar range $\left(\mathrm{GI}_{50}=0.4-1.4 \mu \mathrm{M}\right)$. In this context, we treated both NALM- 6 and REH cell lines with two different concentrations of thiostrepton, 0.5 and $1 \mu \mathrm{M}$, respectively for 24,48 , and $72 \mathrm{~h}$. Results show a significant reduction in cell viability, revealed by the considerable low numbers of trypan blue-negative cells in both NALM-6 and REH cell lines (Figs. 5A and 6A). Moreover, flow cytometric analysis carried out following different treatment times indicates that thiostrepton induces apoptosis, demonstrated by the appearance of a large percentage of Annexin V-positive cells in both cell lines (Figs. 5B and 6B). Importantly, apoptosis occurs in a concentration- and time-dependent manner. In each assay, FOXM1 downregulation was confirmed by both 

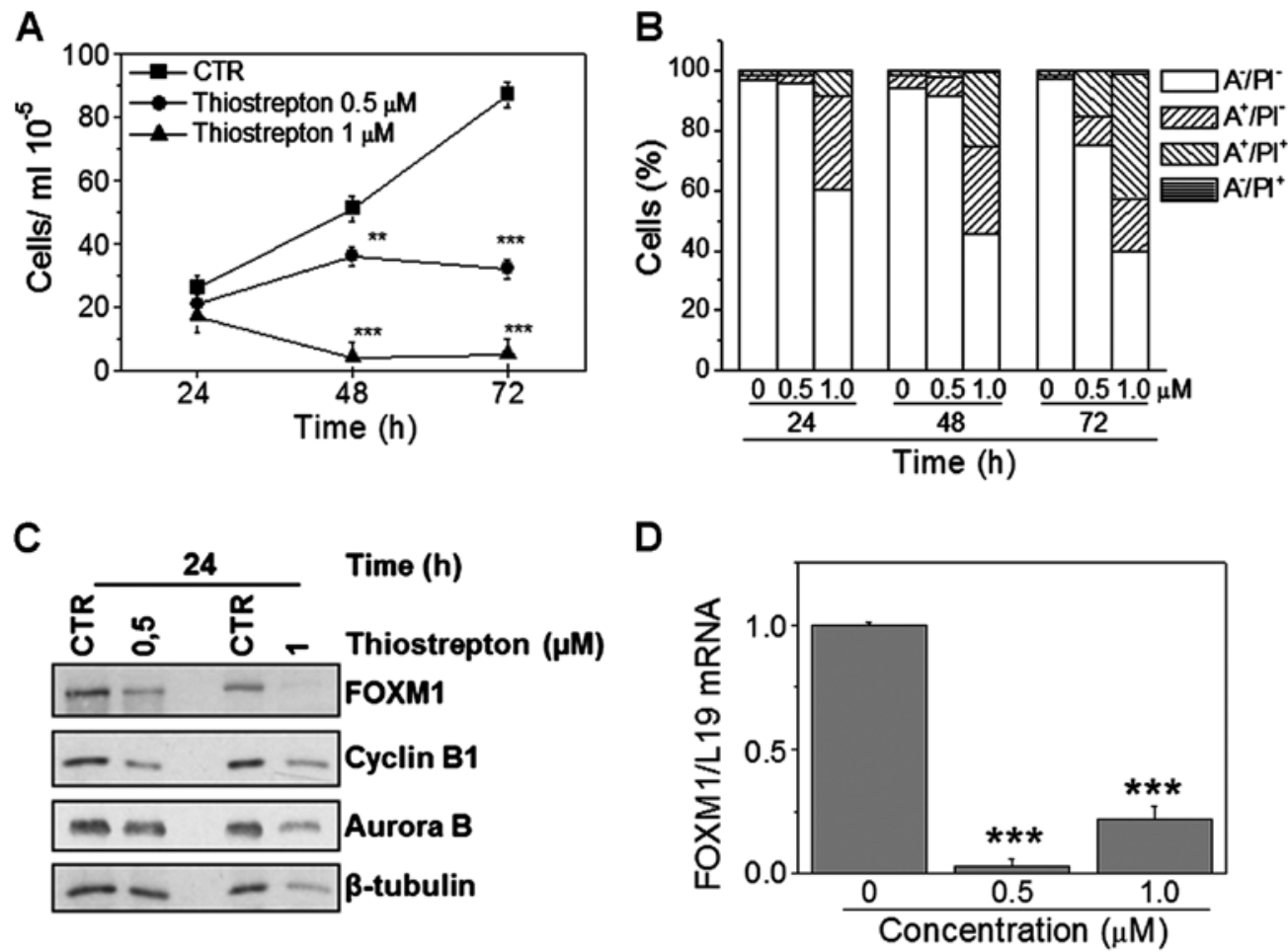

Figure 5. FOXM1 inhibition in NALM-6 cells by thiostrepton treatment induces apoptosis. NALM- 6 cells were treated with thiostrepton at the concentration of 0.5 or $1 \mu \mathrm{M}$, for 24,48 and $72 \mathrm{~h}$. Cell viability analysis was performed by trypan blue assay (A) whereas induction of apoptosis was assessed by flow cytometry after staining of the cells with Annexin V-FITC and propidium iodide (B). Dual staining permits discrimination between live cells (Annexin V-/PI), early apoptotic cells (Annexin $\mathrm{V}^{+} / \mathrm{PI}$ ), late apoptotic cells (Annexin $\mathrm{V}^{+} / \mathrm{PI}^{+}$) and necrotic cells (Annexin $\left.\mathrm{V}^{-} / \mathrm{PI}^{+}\right)$. Western blot (C) and RT-qPCR analysis (D) confirmed that thiostrepton reduces FOXM1 expression. Data are presented as mean \pm SD of three independent experiments. Statistical analysis was performed using Student's t-tests against the control sample (untreated). ${ }^{* *} \mathrm{p} \leq 0.01,{ }^{* * * *} \mathrm{p} \leq 0.001$.

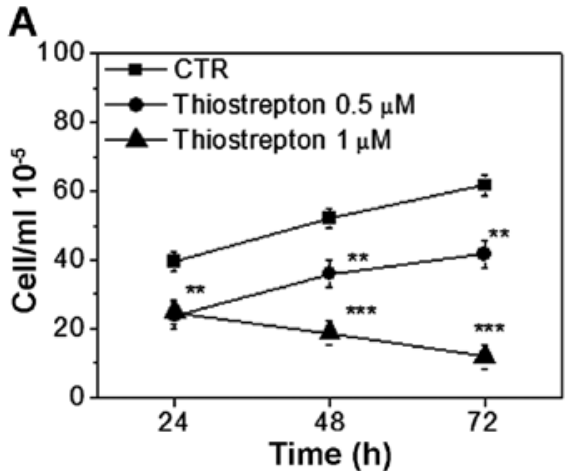

C

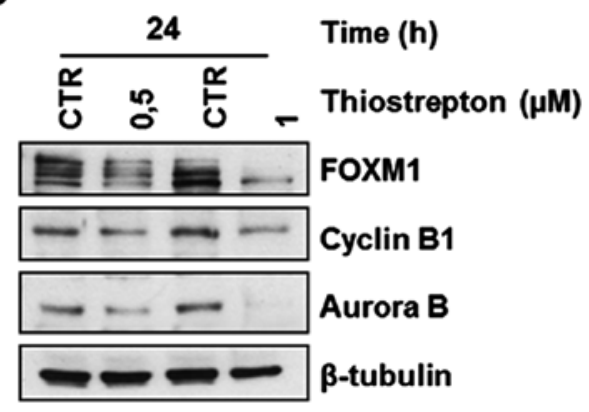

B

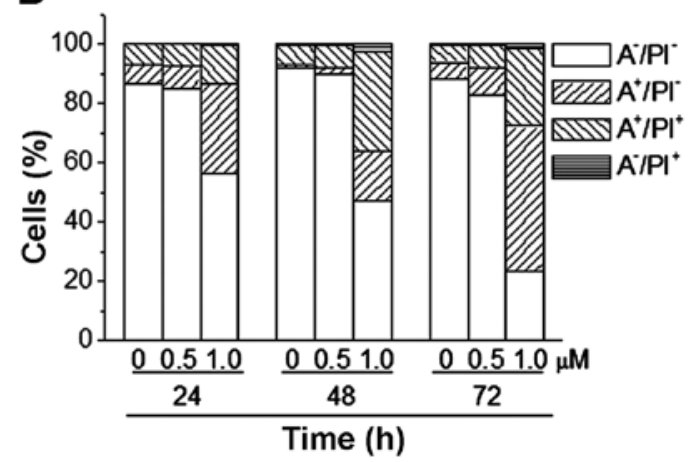

D

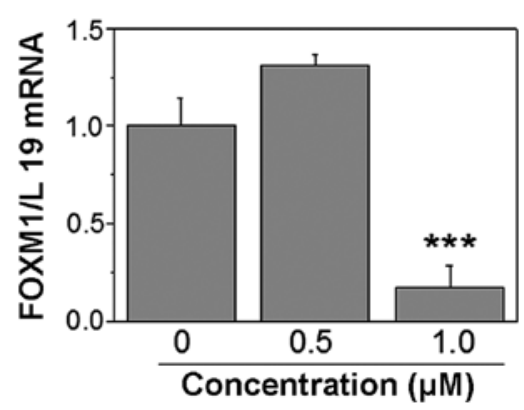

Figure 6. FOXM1 inhibition in REH cells by thiostrepton treatment induces apoptosis. REH cells were treated with thiostrepton at the concentration of 0.5 or $1 \mu \mathrm{M}$, for 24,48 and $72 \mathrm{~h}$. Cell viability analysis was performed by trypan blue assay (A) whereas induction of apoptosis was assessed by flow cytometry after staining of the cells with Annexin V-FITC and propidium iodide (B). Dual staining permits discrimination between live cells (Annexin V-/PI), early apoptotic cells (Annexin $\mathrm{V}^{+} / \mathrm{PI}$ ), late apoptotic cells (Annexin $\mathrm{V}^{+} / \mathrm{PI}^{+}$) and necrotic cells (Annexin $\mathrm{V}^{-} / \mathrm{PI}^{+}$). Western blot (C) and RT-qPCR analysis (D) confirmed that thiostrepton reduces FOXM1 expression. Data are presented as mean \pm SD of three independent experiments. Statistical analysis was performed using Student's t-tests against the control sample (untreated). ${ }^{* *} \mathrm{p} \leq 0.01,{ }^{* * * *} \mathrm{p} \leq 0.001$. 
A
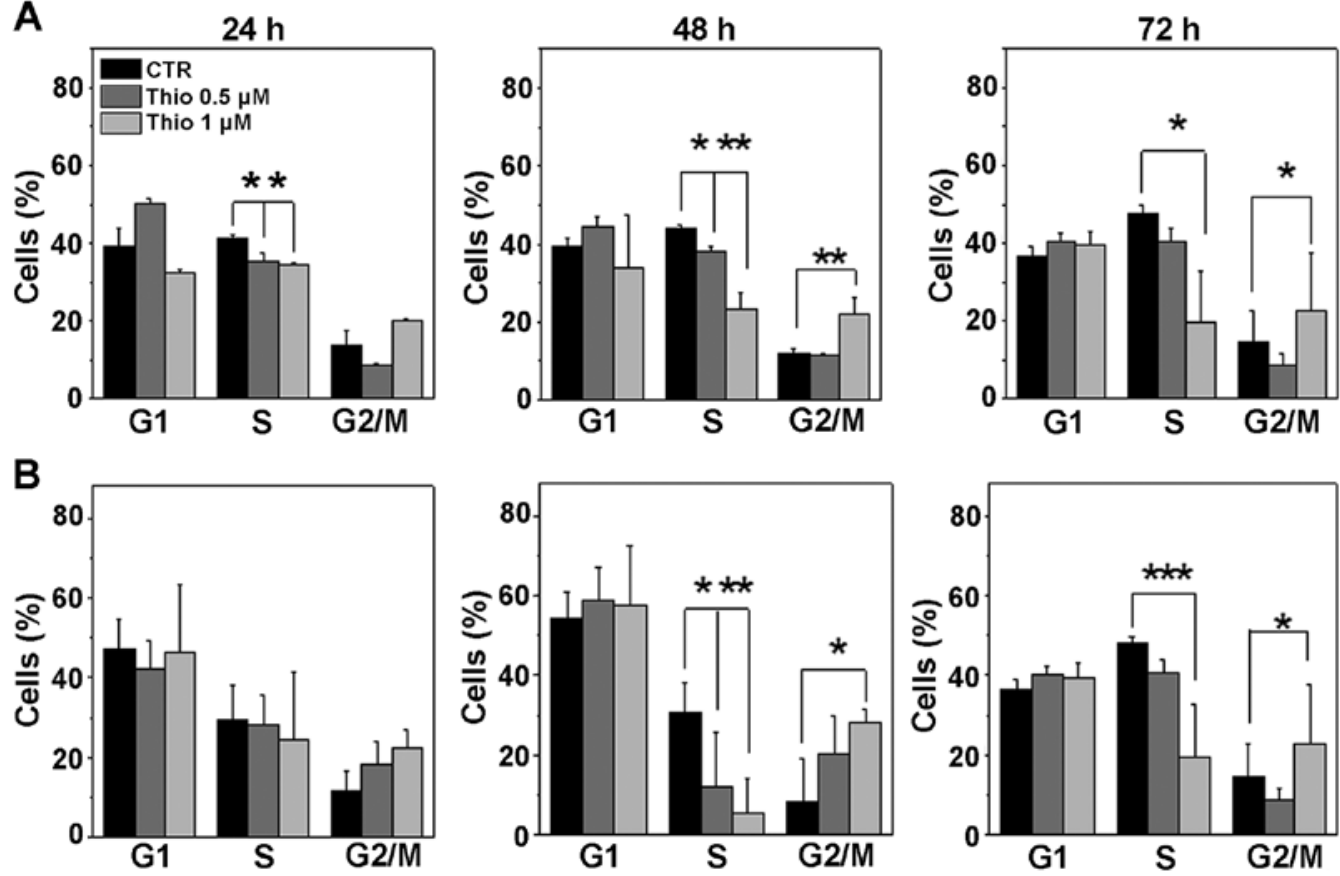

Figure 7. FOXM1 downregulation in REH and NALM6 cells by thiostrepton treatment induces a G2/M cell cycle arrest. NALM-6 (A) and REH cell (B) lines were treated with the indicated concentration of thiostrepton. After 24,48 and $72 \mathrm{~h}$ of treatment, cell cycle analysis was performed to investigate the effect of FOXM1 inhibition in cell cycle-phase progression. Results are the average \pm SD of three independent experiments in triplicate. Statistical analysis was performed using Student's t-tests against the untreated cells. ${ }^{*} \mathrm{p} \leq 0.05,{ }^{* *} \mathrm{p} \leq 0.01,{ }^{* * * *} \mathrm{p} \leq 0.001$
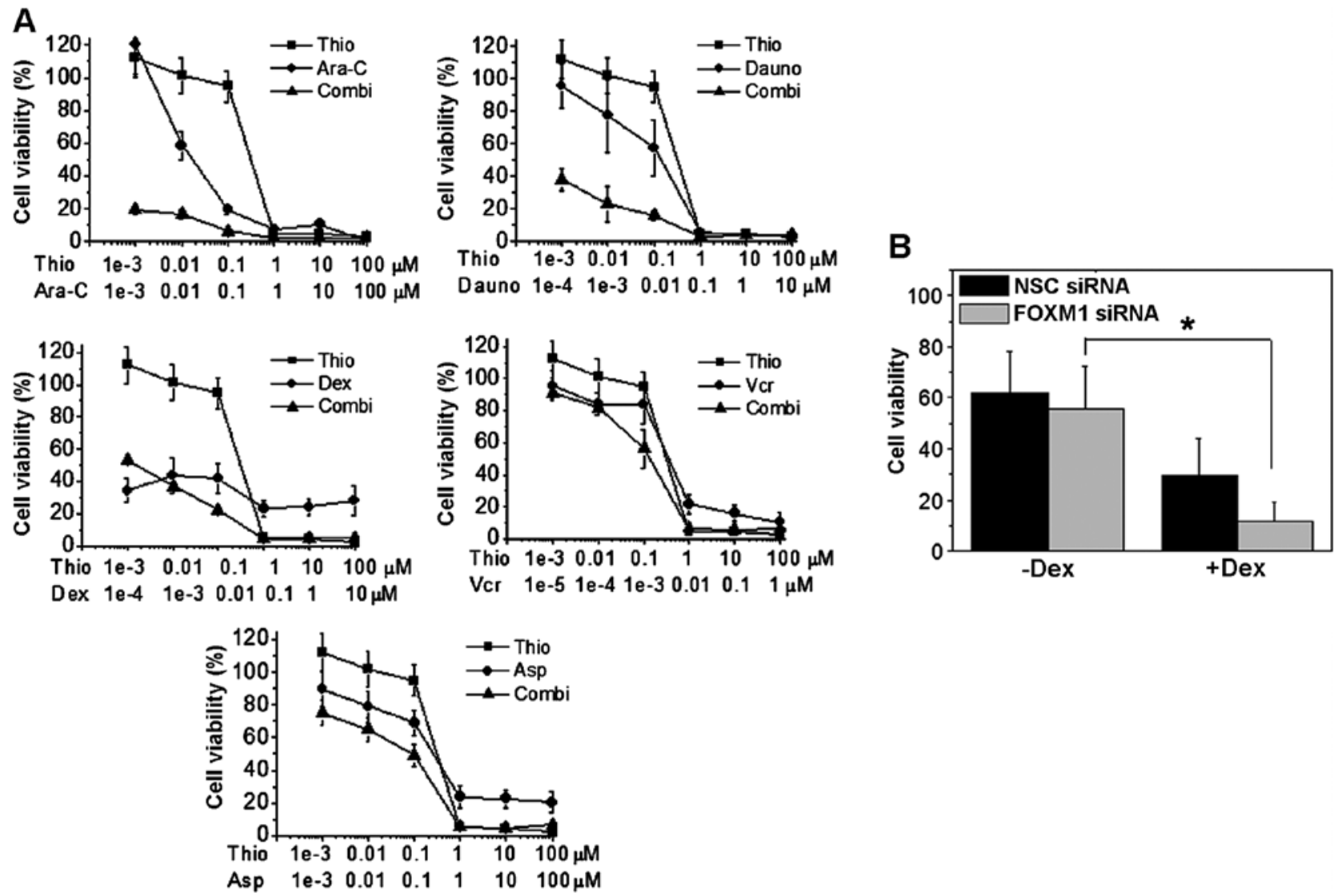

Figure 8. Effect of thiostrepton treatment alone and in combination with different chemotherapic drugs in NALM-6 cells (A). Cells were treated at the indicated concentration and at fixed molar concentration ratio and viability was assessed by MTT-test after $48 \mathrm{~h}$ of incubation. Data are expressed as mean \pm SEM of three independent experiments. (B) NALM- 6 cells were knocked down for FOXM1 and after $48 \mathrm{~h}$ were further treated for $48 \mathrm{~h}$ with dexamethasone at the concentration of $1 \mu \mathrm{M}$. Cell viability was analyzed by flow cytometry after double staining of the cells with Annexin V-FITC and PI. Result are expressed as mean $\pm \mathrm{SD}$ of three independent experiments. Statistical analysis was performed using Student's t-tests against the cells transfected with the non-specific (NSC) siRNA. ${ }^{*} \mathrm{p} \leq 0.01$. 

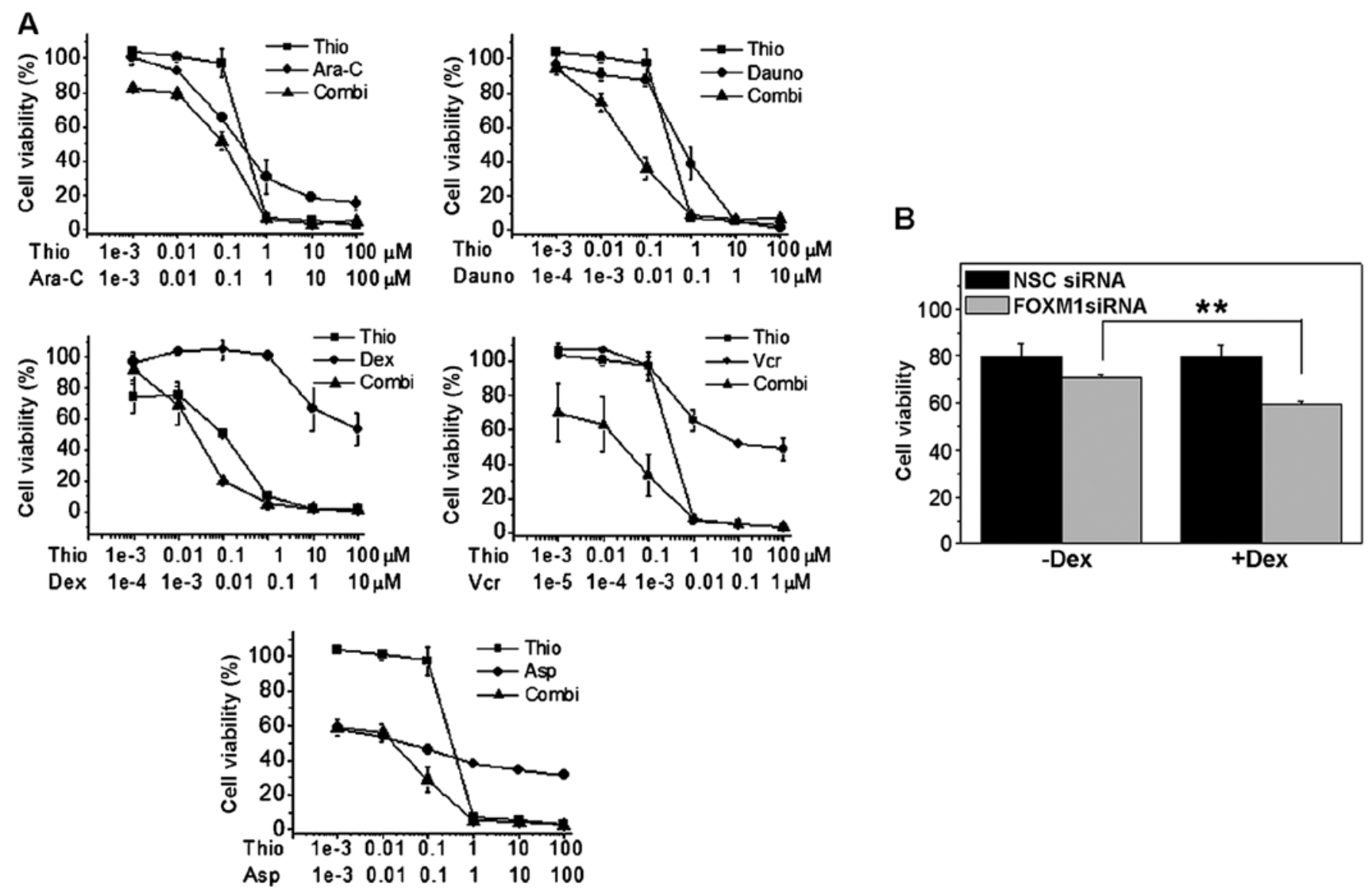

Figure 9. Effect of thiostrepton treatment alone and in combination with different chemotherapic drugs in REH cells (A). Cells were treated at the indicated concentration and at fixed molar concentration ratio and viability was assessed by MTT-test after $48 \mathrm{~h}$ of incubation. Data are expressed as mean \pm SEM of three independent experiments. (B) REH cells were knocked down for FOXM1 and after $48 \mathrm{~h}$ were further treated for $48 \mathrm{~h}$ with dexamethasone at the concentration of $1 \mu \mathrm{M}$. Cell viability was analyzed by flow cytometry after double staining of the cells with Annexin V-FITC and PI. Result are expressed as mean $\pm \mathrm{SD}$ of three independent experiments. Statistical analysis was performed using Student's t-tests against the cells transfected with the non-specific (NSC) siRNA. ${ }^{* *} \mathrm{p} \leq 0.05$.

western blot analysis (Figs. 5C and 6C) and by RT-qPCR (Figs. 5D and 6D). Note that in both cell lines, FOXM1 and its downstream target protein levels were decreased following thiostrepton treatment, in a manner similar to that observed for FOXM1 silencing.

We then analyzed the cell cycle phase distribution in REH and NALM- 6 cells following treatment with both 0.5 and $1 \mu \mathrm{M}$ concentrations of thiostrepton at 24,48 , and $72 \mathrm{~h}$. Results (Fig. 7A and B) show that similarly to FOXM1 knockdown experiments, thiostrepton treatment induces a cellular arrest at the $\mathrm{G} 2 / \mathrm{M}$ cell cycle phase as well as a decrease of cells in the $\mathrm{S}$ phase.

Thiostrepton synergises with conventional chemotherapeutic agents to inhibit B-ALL proliferation. As FOXM1 downregulation led to a decrease on B-ALL cell proliferation, we next-tested if thiostrepton could be used in combination with the most commonly used chemotherapeutics in B-ALL treatment. To this end, four different B-ALL cell lines, two glucocorticoid-resistant (REH, SEM) and two glucocorticoidsensitive (NALM-6, RS4;11), were treated for $48 \mathrm{~h}$ with thiostrepton in combination with chemotherapeutic agents (i.e., dexamethasone, asparaginase, daunorubicin, vincristine and Ara-C) normally used to treat pediatric B-ALL patients. More specifically, thiostrepton was combined with different drugs at fixed molar combination ratios, and cell viability analyzed by MTT assay (Figs. 8A and 9A). As described above, thiostrepton has a significant cytotoxicity when used as single agent. Notably, when thiostrepton was used in combination with chemotherapic drugs, we observed a synergistic increase in the cytotoxicity as demonstrated by the values of combination index (CI) according to Chou and Talalay $(25,30)$. As depicted in Table II, reporting CI values calculated at $\mathrm{GI}_{50}$, $\mathrm{GI}_{75}$ and $\mathrm{GI}_{90}$, in almost all cell lines tested, thiostrepton and chemotherapeutic drugs act in a synergistic fashion $(\mathrm{CI}<1)$. Our results therefore show that, in general, the pharmacological downregulation of FOXM1 caused by thiostrepton, can significantly increase the cell death induced by the treatment with conventional chemotherapeutic agents.

To prove the above further, we knocked down FOXM1 in REH and NALM- 6 cells using siRNA, and then treated them with dexamethasone. After $48 \mathrm{~h}$ of treatment we analyzed cell viability by flow cytometry staining with Annexin $\mathrm{V}$ and propidium iodide (PI). Results showed a significant decrease in cell viability after $48 \mathrm{~h}$ of treatment in FOXM1 silenced cells when compared to its controls, this was particularly noted in 
Table II. Combination index values (CI) in B-ALL cell lines treated with thiostrepton in combination with chemotherapic drugs.

\begin{tabular}{|c|c|c|c|}
\hline & $\mathrm{GI}_{50}^{\mathrm{b}}$ & $\mathrm{GI}_{75}^{\mathrm{b}}$ & $\mathrm{GI}_{90}{ }^{\mathrm{b}}$ \\
\hline \multicolumn{4}{|c|}{ Dauno $(1: 10)^{\mathrm{a}}$} \\
\hline RS4;11 & 2.4 & 0.17 & 0.1 \\
\hline SEM & 0.27 & 0.28 & 0.35 \\
\hline NALM-6 & 0.06 & 0.12 & 0.25 \\
\hline REH & 0.84 & 1.1 & 1.1 \\
\hline \multicolumn{4}{|l|}{ Ara-C $(1: 1)^{\mathrm{a}}$} \\
\hline RS4;11 & 0.07 & 0.2 & 0.006 \\
\hline SEM & 0.33 & 0.35 & 0.42 \\
\hline NALM-6 & 0.0017 & 0.001 & 0.09 \\
\hline REH & 0.16 & 0.29 & 0.54 \\
\hline \multicolumn{4}{|l|}{$\operatorname{Dex}(1: 10)^{\mathrm{a}}$} \\
\hline RS4;11 & 0.10 & 0.9 & 8.0 \\
\hline SEM & 0.18 & 0.15 & 0.13 \\
\hline NALM-6 & 0.8 & 0.044 & 0.24 \\
\hline REH & 1.1 & 0.97 & 0.85 \\
\hline \multicolumn{4}{|c|}{$\operatorname{Vcr}\left(1: 1,000^{\mathrm{a}}\right.$} \\
\hline RS4;11 & 0.04 & 0.02 & 9.5 \\
\hline SEM & 1.1 & 0.75 & 0.6 \\
\hline NALM-6 & 0.64 & 0.44 & 0.74 \\
\hline REH & 0.09 & 0.02 & 0.01 \\
\hline \multicolumn{4}{|l|}{$\operatorname{Asp}(1: 1)^{a}$} \\
\hline RS4;11 & 0.5 & 0.2 & 0.1 \\
\hline SEM & 1.6 & 0.8 & 0.4 \\
\hline NALM-6 & 0.10 & 0.13 & 0.5 \\
\hline REH & 1.3 & 0.05 & 0.15 \\
\hline
\end{tabular}

${ }^{\mathrm{a}}$ Molar ratio with thiostrepton. ${ }^{\mathrm{b}} \mathrm{Growth}$ inhibition determined after $48 \mathrm{~h}$ of treatment by MTT-test. Ara-C, cytarabine; CI, combination index; Dex, dexamethasone; Dauno, daunorubicin; Vcr, vincristine. Synergy, additivity and antagonism are defined by a $\mathrm{CI}<1, \mathrm{CI}=1$ or $\mathrm{CI}>1$, respectively.

glucocorticoid resistant cells, indicating that FOXM1 can be an important therapeutic target for overcoming glucocorticoid resistance in B-ALL (Figs. 8B and 9B).

\section{Discussion}

FOXM1 is an important cell cycle regulator and plays a crucial role in tumorigenesis and its overexpression has been found in many different human cancers. However, very little is known about its function in hematological malignancies. Our aim was to investigate the role of FOXM1 in B-ALL, the most common pediatric leukemia. RT-PCR analysis performed on ten B-ALL patient samples showed that FOXM1 mRNA is highly overexpressed in comparison to FOXM1 mRNA from lymphocytes of healthy donors and more importantly also in comparison with normal B-cells $\left(\mathrm{CD}^{+} 9^{+}\right)$. These results are in excellent agreement with Buchner et al (20) who recently showed that FOXM1 is highly overexpressed in B-ALL irrespectively of different B-ALL subsets. It is important to note that our primers, irrespectively detect both $\mathrm{B}$ and $\mathrm{C}$ isoforms of FOXM1 which represent the active forms since the isoform FOXM1A, is not translated.

The pattern of FOXM1 is mirrored by Cyclin B1 and Aurora B, two G2/M phase regulators directly regulated by FOXM1. Immunoblot analysis also demonstrated similar overexpression of FOXM1 and its downstream targets in samples from blast patients, suggesting that FOXM1 is also aberrantly overexpressed in B-ALL as in many other cancer types. In agreement, the five B-ALL cell lines analyzed also overexpressed FOXM1 and its downstream targets, confirming the results obtained in patients. Importantly, our study revealed that the FOXM1 depletion by siRNA causes a significant reduction in the proliferation rate of $\mathrm{B}-\mathrm{ALL}$ cell lines, suggesting a role for FOXM1 in the oncogenesis of B-ALL. Moreover, FOXM1 silencing led to cell cycle arrest in G2/M, suggesting that FOXM1 promotes cell proliferation through cell-cycle modulation, previously reported by Nakamura et al in acute myeloid leukemia cells (16). Consistent with previous data (16), FOXM1 silencing in B-ALL cell lines led to a downregulation of proteins involved in the regulation of mitotic progression. We also showed that FOXM1 silencing is accompanied by a decrease on expression levels of $\mathrm{p} 27^{\mathrm{Kip} 1}$ and $\mathrm{p} 21^{\mathrm{Cip} 1 /}$ Waf1 proteins, which are known to assemble different Cyclin/ Cdk complexes. $\mathrm{p} 27^{\mathrm{Kip} 1}$ and $\mathrm{p} 21^{\mathrm{Cip} 1 / \text { Waf1 }}$ proteins are phosphorylated by the Cdk2-cyclin E complex, to be recognized by the specificity subunits Skp2 and Cks1 of the SCF ubiquitin ligase complex, which targets them for ubiquitin-mediated proteasome degradation (31-33). It could therefore be speculated that the noted decrease in their expression could reflect an accelerated ubiquitinylation and subsequent degradation.

Thiostrepton is a thiazole antibiotic that inhibits the transcriptional activity of FOXM1. It also downregulates FOXM1 mRNA expression, since FOXM1 can positively auto-regulate its own transcription $(28,34)$. Indeed, we found that both the mRNA and protein expression of FOXM1 were downregulated by thiostrepton in B-ALLs. In our study, we also found that thiostrepton remarkably reduces the cell viability of different B-ALL cell lines causing apoptosis in a concentration- and time-dependent manner, as well as inducing a G2/M arrest of the cell cycle, consistent with the result obtained with the siRNA-mediated knockdown of FOXM1.

The standard treatment option for newly diagnosed childhood B-ALL is predominantly chemotherapy. Patients that respond poorly to chemotherapy are predicted to undergo a future relapse. Understanding the biological mechanisms which underlie poor responsiveness is therefore crucial for the development of more effective therapies. Consistent with this, Bhatla et al have identified in a cohort of relapsed B-ALL pediatric patients a series of upregulated genes which also includes FOXM1 (21).

In light of these results we examined if combining thiostrepton with the chemotherapeutics used in B-ALL therapy could increase their efficacy. Our results clearly indicate a strong synergistic effect $(\mathrm{CI}<1)$ between thiostrepton and drugs with different mechanisms of action in the four B-ALL cell lines tested. Our results are in good agreement with that reported by Uddin et al who reported a synergistic interac- 
tion of thiostrepton with bortezomib in diffuse large B-cell lymphoma (18). It is also important to note that thiostrepton is able to partially reverse the glucocorticoid resistance in REH cells. These results were further confirmed, in a more specific way, in the same cell lines with silenced FOXM1 (Figs. 8B and $9 \mathrm{~B})$. Given that patients that respond poorly to glucocorticoid therapy at diagnosis are usually predicted to undergo relapse in the future, our findings suggest that FOXM1 inhibition could be a potential useful strategy in clinical therapy to optimize the efficacy of existing therapeutics for B-ALL, although further studies are needed to better understand the molecular mechanism(s) involved in these synergistic effects. Indeed, very recently Buchner et al (20) reported the efficacy of thiostrepton also in vivo in a mouse xenograft model of B-ALL. In conclusion, we show that FOXM1 has a role in both oncogenesis and the development of drug resistance in B-ALL, and the targeting of FOXM1 could be a useful means for treating B-ALL and for overcoming drug resistance.

\section{References}

1. Lam EW-F, Brosens JJ, Gomes AR and Koo C-Y: Forkhead box proteins: Tuning forks for transcriptional harmony. Nat Rev Cancer 13: 482-495, 2013.

2. Laoukili J, Kooistra MRH, Brás A, Kauw J, Kerkhoven RM, Morrison A, Clevers H and Medema RH: FoxM1 is required for execution of the mitotic programme and chromosome stability. Nat Cell Biol 7: 126-136, 2005.

3. Laoukili J, Alvarez M, Meijer LA, Stahl M, Mohammed S, Kleij L, Heck AJ and Medema RH: Activation of FoxM1 during G2 requires cyclin $\mathrm{A} / \mathrm{Cdk}$-dependent relief of autorepression by the FoxM1 N-terminal domain. Mol Cell Biol 28: 3076-3087, 2008.

4. Wang I-C, Chen Y-J, Hughes D, Petrovic V, Major ML, Park HJ, Tan Y, Ackerson T and Costa RH: Forkhead box M1 regulates the transcriptional network of genes essential for mitotic progression and genes encoding the SCF (Skp2-Cks1) ubiquitin ligase. Mol Cell Biol 25: 10875-10894, 2005.

5. Gemenetzidis E, Elena-Costea D, Parkinson EK, Waseem A, Wan $\mathrm{H}$ and Teh M-T: Induction of human epithelial stem/progenitor expansion by FOXM1. Cancer Res 70: 9515-9526, 2010.

6. Huynh KM, Soh J-W, Dash R, Sarkar D, Fisher PB and Kang D: FOXM1 expression mediates growth suppression during terminal differentiation of HO-1 human metastatic melanoma cells. J Cell Physiol 226: 194-204, 2011.

7. Wang Z, Park HJ, Carr JR, Chen YJ, Zheng Y, Li J, Tyner AL, Costa RH, Bagchi S and Raychaudhuri P: FoxM1 in tumorigenicity of the neuroblastoma cells and renewal of the neural progenitors. Cancer Res 71: 4292-4302, 2011.

8. Monteiro LJ, Khongkow P, Kongsema M, Morris JR, Man C, Weekes D, Koo CY, Gomes AR, Pinto PH, Varghese V, et al: The Forkhead Box M1 protein regulates BRIP1 expression and DNA damage repair in epirubicin treatment. Oncogene 32: 4634-4645, 2013.

9. Khongkow P, Karunarathna U, Khongkow M, Gong C, Gomes AR, Yagüe E, Monteiro LJ, Kongsema M, Zona S, Man EP, et al: FOXM1 targets NBS1 to regulate DNA damage-induced senescence and epirubicin resistance. Oncogene 33: 4144-4155, 2014.

10. Li X, Qiu W, Liu B, Yao R, Liu S, Yao Y and Liang J: Forkhead box transcription factor 1 expression in gastric cancer: FOXM1 is a poor prognostic factor and mediates resistance to docetaxel. J Transl Med 11: 204, 2013.

11. Chu X-Y, Zhu Z-M, Chen L-B, Wang JH, Su QS, Yang JR, Lin Y, Xue LJ, Liu XB and Mo XB: FOXM1 expression correlates with tumor invasion and a poor prognosis of colorectal cancer. Acta Histochem 114: 755-762, 2012.

12. Martin KJ, Patrick DR, Bissell MJ and Fournier MV: Prognostic breast cancer signature identified from 3D culture model accurately predicts clinical outcome across independent datasets. PLoS One 3: e2994, 2008.

13. Bektas N, Haaf A, Veeck J, Wild PJ, Lüscher-Firzlaff J, Hartmann A, Knüchel R and Dahl E: Tight correlation between expression of the Forkhead transcription factor FOXM1 and HER2 in human breast cancer. BMC Cancer 8: 42, 2008.
14. Xia L, Huang W, Tian D, Zhu H, Zhang Y, Hu H, Fan D, Nie Y and Wu K: Upregulated FoxM1 expression induced by hepatitis B virus $\mathrm{X}$ protein promotes tumor metastasis and indicates poor prognosis in hepatitis B virus-related hepatocellular carcinoma. J Hepatol 57: 600-612, 2012.

15. Liu M, Dai B, Kang S-H, Ban K, Huang FJ, Lang FF, Aldape KD, Xie TX, Pelloski CE, Xie K, et al: FoxM1B is overexpressed in human glioblastomas and critically regulates the tumorigenicity of glioma cells. Cancer Res 66: 3593-3602, 2006.

16. Nakamura S, Hirano I, Okinaka K, Takemura T, Yokota D, Ono T, Shigeno K, Shibata K, Fujisawa S and Ohnishi K: The FOXM1 transcriptional factor promotes the proliferation of leukemia cells through modulation of cell cycle progression in acute myeloid leukemia. Carcinogenesis 31: 2012-2021, 2010.

17. Wang Z, Zheng Y, Park HJ, Li J, Carr JR, Chen YJ, Kiefer MM, Kopanja D, Bagchi S, Tyner AL, et al: Targeting FoxM1 effectively retards p53-null lymphoma and sarcoma. Mol Cancer Ther 12: 759-767, 2013

18. Uddin S, Hussain AR, Ahmed M, Siddiqui K, Al-Dayel F, Bavi P and Al-Kuraya KS: Overexpression of FoxM1 offers a promising therapeutic target in diffuse large B-cell lymphoma. Haematologica 97: 1092-1100, 2012.

19. Zhao B, Barrera LA, Ersing I, Willox B, Schmidt SC, Greenfeld H, Zhou H, Mollo SB, Shi TT, Takasaki K, et al: The $\mathrm{NF}-\kappa \mathrm{B}$ genomic landscape in lymphoblastoid B cells. Cell Rep 8: 1595-1606, 2014.

20. Buchner M, Park E, Geng H, Klemm L, Flach J, Passegué E, Schjerven H, Melnick A, Paietta E, Kopanja D, et al: Identification of FOXM1 as a therapeutic target in B-cell lineage acute lymphoblastic leukaemia. Nat Commun 6: 6471, 2015.

21. Bhatla T, Wang J, Morrison DJ, Raetz EA, Burke MJ, Brown P and Carroll WL: Epigenetic reprogramming reverses the relapsespecific gene expression signature and restores chemosensitivity in childhood B-lymphoblastic leukemia. Blood 119: 5201-5210, 2012.

22. Accordi B, Galla L, Milani G, Curtarello M, Serafin V, Lissandron V, Viola G, te Kronnie G, De Maria R, Petricoin EF III, et al: AMPK inhibition enhances apoptosis in MLL-rearranged pediatric B-acute lymphoblastic leukemia cells. Leukemia 27: 1019-1027, 2013.

23. Hui RC-Y, Gomes AR, Constantinidou D, Costa JR, Karadedou CT, Fernandez de Mattos S, Wymann MP, Brosens JJ, Schulze A and Lam EW: The forkhead transcription factor FOXO3a increases phosphoinositide-3 kinase/Akt activity in drug-resistant leukemic cells through induction of PIK3CA expression. Mol Cell Biol 28: 5886-5898, 2008.

24. Bortolozzi R, Viola G, Porcù E, et al: A novel copper (I) complex induces ER-stress-mediated apoptosis and sensitizes B-acute lymphoblastic leukemia cells to chemotherapeutic agents. Oncotarget 5: 5978-5991, 2014.

25. Chou T-C: Drug combination studies and their synergy quantification using the Chou-Talalay method. Cancer Res 70: 440-446, 2010.

26. Nilsson I and Hoffmann I: Cell cycle regulation by the $\mathrm{Cdc} 25$ phosphatase family. Prog Cell Cycle Res 4: 107-114, 2000.

27. Bertoli C, Skotheim JM and de Bruin RAM: Control of cell cycle transcription during G1 and S phases. Nat Rev Mol Cell Biol 14: 518-528, 2013.

28. Kwok JM-M, Myatt SS, Marson CM, Coombes RC, Constantinidou D and Lam EW-F: Thiostrepton selectively targets breast cancer cells through inhibition of forkhead box M1 expression. Mol Cancer Ther 7: 2022-2032, 2008.

29. Hegde NS, Sanders DA, Rodriguez R and Balasubramanian S: The transcription factor FOXM1 is a cellular target of the natural product thiostrepton. Nat Chem 3: 725-731, 2011.

30. Chou TC: Theoretical basis, experimental design, and computerized simulation of synergism and antagonism in drug combination studies. Pharmacol Rev 58: 621-681, 2006.

31. Carrano AC, Eytan E, Hershko A and Pagano M: SKP2 is required for ubiquitin-mediated degradation of the $\mathrm{CDK}$ inhibitor p27. Nat Cell Biol 1: 193-199, 1999.

32. Hara T, Kamura T, Nakayama K, Oshikawa K, Hatakeyama $S$ and Nakayama K: Degradation of p27(Kip1) at the G(0)-G(1) transition mediated by a Skp2-independent ubiquitination pathway. J Biol Chem 276: 48937-48943, 2001.

33. Lu Z and Hunter T: Ubiquitylation and proteasomal degradation of the p21(Cip1), p27(Kip1) and p57(Kip2) CDK inhibitors. Cell Cycle 9: 2342-2352,2010.

34. Koo C-Y, Muir KW and Lam EW-F: FOXM1: From cancer initiation to progression and treatment. Biochim Biophys Acta 1819: 28-37, 2012. 